\title{
Publishing and perishing: an academic literacies framework for investigating research productivity
}

\section{Lynn P. Nygaard}

To cite this article: Lynn P. Nygaard (2017) Publishing and perishing: an academic literacies framework for investigating research productivity, Studies in Higher Education, 42:3, 519-532, DOI: 10.1080/03075079.2015.1058351

To link to this article: https://doi.org/10.1080/03075079.2015.1058351

\section{(c) 2015 The Author. Published by Taylor \& Francis.}

\section{Published online: 10 Jul 2015.}

Submit your article to this journal

\section{Џll Article views: 2592}

Q View related articles $\widetilde{ }$

View Crossmark data $\nearrow$

4 Citing articles: 9 View citing articles 


\title{
Publishing and perishing: an academic literacies framework for investigating research productivity
}

\author{
Lynn P. Nygaard ${ }^{\mathrm{a}, \mathrm{b} *}$ \\ ${ }^{a}$ Peace Research Institute Oslo (PRIO), P.O. Box 9229 Grønland, 0134 Oslo, Norway; \\ ${ }^{b}$ Institute of Education, University College London, London, UK
}

\begin{abstract}
The current discourse on research productivity (how much peer-reviewed academic output is published by faculty) is dominated by quantitative research on individual and institutional traits; implicit assumptions are that academic writing is a predominately cognitive activity, and that lack of productivity represents some kind of deficiency. Introducing the academic literacies approach to this debate brings issues of identity, multiple communities, and different institutional expectations (at the local, national, and international levels) to the foreground. I argue that academics often juggle competing demands that create various sites of negotiation in the production of academic writing: the results of these negotiations can have a direct impact on what kind of research output is produced, and how much it 'counts'. Drawing from research on the Peace Research Institute Oslo (PRIO), this article demonstrates how a theoretical framework based on academic literacies can be used to investigate research productivity outcomes in specific academic settings.
\end{abstract}

Keywords: academic literacies; academic publishing; academic staff; academic writing; research writing

\section{Introduction}

The expression 'publish or perish' has been around since the 1930s, reflecting the reality that academics face: to make it in academia, you have to publish regularly. And yet - according to research productivity indicators - there seems to be more perishing than publishing for the majority of researching academics. Throughout the world, in virtually every higher education or research setting, the numbers show that a small minority of researchers produce the vast majority of the publications, while most researchers publish little or nothing at all (Kyvik 1991; Teodorescu 2000). In connection with the increasing need to document, measure, and demonstrate success (Alexander 2000), these numbers have resulted in hand-wringing and finger-pointing as we look for solutions to 'fix' what has apparently gone so very wrong.

Academic literacies theory was developed in direct response to a parallel 'deficit model' of student writing (Lillis and Scott 2007). Stemming from New Literacy Studies (Lea and Street 1998), it challenges the notion that academic writing is simply a matter of achieving a particular set of cognitive skills that can be used from one context to the next (Lea 2004; Lea and Street 1998). Rather, it sees academic

\footnotetext{
*Email: lynn@prio.org
} 
writing as a social practice, bringing to the forefront aspects of student writing that had been previously ignored: power relations, identity, and ideologically inscribed knowledge construction (Lea and Street 1998, 2006; Lillis 2003). Although developed primarily to look at student writing, the academic literacies approach can be fruitfully extended to investigate professional academic writing (see, e.g. Lillis and Curry 2010, 2006). Just as student writing is a 'high stakes' activity in higher education (Lillis and Scott 2007), so too is faculty writing: the funding and reputation of the university often depend on the academic output of its staff.

By seeing writing as a situated practice, socially embedded within a specific community (or communities) (Barton, Hamilton, and Ivanic 2000), the academic literacies perspective directs our gaze to issues of identity (and beliefs about the self), and acknowledges that people belong to more than one community at a time - and these communities may have conflicting expectations. Researchers may feel they belong not just to the institute they are employed by, but also to a larger discipline-focused community (e.g. other political scientists or anthropologists), a larger thematic community (those who share interest in the same topic), a linguistic or national community (people who share the same language, ethnicity, or nationality), and any number of social communities (e.g. church, political organization, gay community, feminist community, etc.) (Flower 1994; Ivanic 1998). In other words, although academic writing is situated, it is situated at local, national, and international levels (Brandt and Clinton 2002), all of which may have different conceptualizations of academic writing and productivity.

Juggling between aspects of identity and various expectations from different spheres results in what various authors have referred to as sites of negotiation in the production of scholarly writing (Flower 1994; Street 2003; Trede, Macklin, and Bridges 2012). A site of negotiation is where writers face competing demands from outside voices as well as multiple (and perhaps competing) personal goals, requiring them to develop strategies and practices to cope with making choices before, during, and after the production of academic text - as well as in the text itself (Flower 1994). In other words, the academic literacies perspective opens up for the possibility that an apparent lack of productivity might not stem from 'cognitive deficit' or 'falling standards,' but rather from the outcome of a negotiation that did not result in publishing output that 'counts.' For example, researchers who give priority to applied research and direct communication with user groups may produce reports that are valued by the target audience, but not reflected in productivity statistics.

This article takes a point of departure in one specific research environment, the Peace Research Institute Oslo (PRIO), to explore the theoretical implications of using the academic literacies perspective to understand research productivity. First, I give an overview of the dominant discourse in research productivity, pointing to gaps that an academic literacies perspective can fill. I then use the case of PRIO to illustrate the kinds of insights that an academic literacies perspective can bring to the discourse. By analysing the sites of negotiation that arise for my informants and the strategies they develop, I aim to illustrate how researchers negotiate between conflicting demands - and how these outcomes can affect productivity statistics. Finally, I present a theoretical model that can integrate the academic literacies perspective into the ongoing research productivity discourse. I argue that this model can be used to explore sites of negotiation in other research settings, and add to our understanding of why some researchers seem to produce more than others. 


\section{Researching research productivity: the dominant approaches}

A considerable amount of research has been done on the topic of research productivity, starting from about the mid-1970s. Currently, the bulk of this research is quantitative in nature and attempts to tease out the relative explanatory power of individual traits such as gender, age, rank, or discipline (see, e.g. Bentley 2011; Piro, Aksnes, and Rørstad 2013; Teodorescu 2000). Factors related to the institutional setting have also been explored extensively. Bland and Ruffin (1992), for example, cite clear goals, research emphasis, positive culture, accessible resources, sufficient size, balance of age and diversity, and appropriate rewards as key factors for a productive institutional environment. The importance of institutional support for research has been reiterated frequently (Creamer 1998; Fairweather 2002; White et al. 2012). Few studies have looked at how individual and institutional characteristics interact, however, and how individuals manage conflicting goals or priorities. Notable exceptions are Blackburn and Bentley (1993), who argue that not only are clear institutional goals important, but they have to be in line with the individual's own goals, otherwise stress results. Similarly, Williams and Kotrlik (2004) find that both the perception of organizational priorities and perception of one's own abilities affect how academics prioritize. None that I have seen, however, conceptualize the institutional environment as anything more than the institution in which the researcher is employed.

The research productivity literature as a whole also suffers from two other key weaknesses. First, with few exceptions (notably Piro, Aksnes, and Rørstad 2013), these studies do not operate with comparable - or sometimes even clear - measures of productivity. Some rely on vague 'self-reported' data gathered through a general survey. Others gather data systematically, but it is not always clear how it was measured: for example, whether books are given the same weight as articles, or whether co-authored works count as much as solo-authored works. Decisions about what kinds of publication 'count,' and how these things should be counted are not simply technicalities: these decisions reflect assumptions about what is valued in the particular academic setting (such as publication in prestigious journals), what is easy or difficult (writing books or book chapters versus writing articles), and what is the fairest way to compare productivity across research environments. The academic literacies perspective brings to the forefront how conceptualizations of productivity and how to measure it reflect dominant ideologies about what academic research and writing is.

Second, there is little reference to theory, with the exception of the literature focusing on motivation (e.g. Williams and Kotrlik 2004). Here, social cognitive theory (see, e.g. Bandura 1991) is the dominant voice. Social cognitive theory proposes that individuals do not just mindlessly react to their environments or follow some sort of biological imperative, but that - based on their beliefs about their environment and themselves - they set goals, make strategies, and consciously act to achieve a desired outcome (Bandura 1991). While helpful for understanding specific attitudes and behaviors related to writing, its usefulness in the context of research productivity is limited by the apparent assumption that both the individual's and the environment's value sets are clear, consistent, rational, and unitary. The academic literacies perspective acknowledges that conflict may arise not only between self and environment, but between two different environments each exerting pressure on the individual, or between one aspect of self and another aspect of self. 


\section{The research site}

PRIO is located in Oslo, Norway, and has a research staff of about 60 person-years. PRIO is one of 26 social science institutes in Norway's independent institute sector, which is responsible for the bulk of the applied research in Norway.

Research productivity in Norway is measured using a complex bibliometric-based system that awards points exclusively to journal articles, books (monographs, not edited volumes), and book chapters. The points are weighted both by the type of output (with books getting most points and book chapters the least) and by 'quality' (where works published in high-ranking journals and presses are given extra points). In addition to the weighting, publication points are also fractionalized by author (i.e. each author receives a proportional share of the points). These data are used to calculate the core grants of all research-producing institutes.

PRIO provides an excellent context for exploring how researchers process competing sets of goals that might affect productivity: As an independent research institute, PRIO provides applied, policy-relevant research to a broader audience, but like all research-producing institutes in Norway receives credit only for its academic output. These tensions are reflected in the somewhat mixed signals from PRIO's institutional environment. While strategy documents emphasize the importance of communicating with the general public and user groups in addition to other academics, only academic outputs count in the productivity indicators and are literally rewarded: PRIO researchers are awarded NOK 4400 for chapters in anthologies, NOK 13,200 for journal articles, and NOK 35,200 for books. This suggests that PRIO straddles, at times uncomfortably, what Gibbons et al. (1994, 99) call Mode 1 and Mode 2 knowledge production: PRIO's policy-relevant and interdisciplinary research is consistent with what they describe as Mode 2; yet productivity is conceptualized exclusively in terms of published academic output, which is more consistent with what they describe as Mode 1 (a traditional university setting).

\section{Methodological approach: identifying sites of negotiation}

This study builds on doctoral research carried out at the Institute of Education, University College London (Nygaard 2014b), which in turn builds on observations I have made as PRIO's special advisor on project development and publications. My position at PRIO can best be described as what Lillis and Curry $(2006,2010)$ call a 'literacy broker'; I assist researchers with academic publishing and grant writing by giving feedback on text, as well as running writing workshops, retreats, and groups (Nygaard 2014a). My role as an insider and practitioner gives me access to generalized knowledge about productivity, strategic goals, and publication practices at PRIO. The doctoral research allowed me to explore productivity from the perspective of the individual researcher.

Consistent with the epistemological stance of academic literacies (Lillis and Scott 2007), I took a broadly defined ethnographic approach to analyzing academic writing and research productivity as a social practice. Rather than focusing on the text itself, I focused on the attitudes and beliefs that shape the choices researchers make in the process of producing academic output. In other words, the unit of analysis is the individual researchers operating within PRIO as an institutional setting.

I focused on a volunteer group of 19 researchers with at least a $50 \%$ position at PRIO. The composition of the group roughly reflected PRIO's composition with 
respect to gender, discipline, methodological orientation, language background, and rank. Everyone in the group participated in a semi-structured interview (averaging about 90 minutes each) covering a wide range of issues related both to academic writing in general and to specific texts they had produced. Observations I made as a practitioner formed the basis of the questions I asked in the interviews, and the interviews themselves represented an extraordinary opportunity for both me and the researchers to actively reflect on the nature of academic writing and publishing (Hockey and Forsey 2012). I followed up the interviews with further informal discussions and observation, and used a simple questionnaire about some key themes to triangulate and compare responses.

Using NVivo, I analyzed the interviews thematically, looking for the variety of ways in which my informants described (i) themselves, both as writers and people; (ii) their social environment, also beyond PRIO, including how they understand the basic nature of academic writing; and (iii) particular sites of negotiation, that is, any situations in which they felt they had to weigh one set of considerations against another. I was interested in tensions not only between individual identity and the perceived environment, but also between different aspects of identity and different aspects of the environment. I also looked for ways in which they coped with these tensions.

\section{Sites of negotiation at PRIO}

Based on the wide range of themes that emerged from the data, I categorized the sites of negotiation reported by PRIO researchers into the following four main themes that relate directly to how productivity is measured in this setting: genre (what kind of output to produce), collaboration (whether or not to co-author), quality (how high to aim), and process (how to produce text). Below I describe key negotiations reported by my informants within these themes, as well as some coping strategies (all names are pseudonyms). Although I point to some general trends with respect to groups (e.g. junior versus senior researchers, or qualitatively versus quantitatively oriented researchers), I make no claims about statistical significance. These examples are merely intended to illustrate how, as a social practice, writing and publishing is experienced differently by different groups.

\section{Genre}

It is not always obvious what form research output should take, but the choice the author makes determines whether or not (or how much) the output 'counts' in the productivity statistics. As described above, only peer-reviewed journal articles, books, or book chapters are included in Norway's productivity measures and rewarded at PRIO. However, peace research in general, and some funders in particular, demand a wider range of outputs: policy briefs, reports, opinion pieces aimed at the general public, and so on. The interview data showed that decisions about genre were often difficult, first and foremost because some types of written output seemed to be more valued than others (Lea and Stierer 2009; Lillis and Curry 2010).

Most everyone felt that journal articles were the most valued output at PRIO - even to the extent that the other acceptable forms of academic output (books and book chapters) were looked down upon. This belief is reinforced by the PRIO publications reward for a journal article being disproportionately high compared to the national point 
system. While none of the informants claimed that the monetary reward was important for motivation, everyone received the message that articles matter more than book chapters, or even books. Nina, for example, said that 'the evaluation of academics ... I feel is getting more and more focused on peer reviewed journal articles.' This means that those who come from a disciplinary tradition that values the book format sometimes feel uncomfortable about what they often see as a narrow focus on articles. Both Harald and Susan felt this particular squeeze. Harald sees the article as a 'work-inprogress type of publication,' while 'a book or a monograph is a little bit more definite. That's when it's supposed to be more of a long-lasting value.' Harald mentioned that he was thinking of writing a book, but said - albeit in a joking tone - that it would be a kind of rebellion. Susan described how the most satisfying piece she had written was the book based on her doctoral research, but that she felt she should focus on journal article writing to build up her portfolio. Thus, the decision to write a book sometimes represents an outcome of a negotiation where personal goals or larger disciplinary identity 'wins' over perceived institutional expectations.

Negotiations were also involved in producing something that does not count at all in the productivity indicators (Lea and Stierer 2009). For PRIO researchers, this would include grant writing, writing for policy-makers, and writing for the general public.

PRIO researchers depend on external sources of funding, and are required to bring in enough grants to cover their activities; the capricious nature of the funding environment means that individual researchers are highly vulnerable to funding cycles. Pernille described how lack of funding can severely undermine a researcher's confidence in their own competence as a researcher. Although that confidence can be boosted through academic publishing that 'counts,' most informants feel pressured to prioritize grant writing if they do not have enough funding to cover their hours. The negotiation here hangs on whether researchers feel it is more important to bolster their own individual productivity rates or add to the collective income through grant raising. Some research suggests that there might be a gender dimension to this negotiation between the individual and collective good (see, e.g. Acker and Armenti 2004). What is more certain is the oft-cited Mathew effect, where resources (both grants and awards) tend to go to those who already have them (Merton 1968), and these resources may play an important role in the skewed productivity statistics (see, e.g. Creamer 1998) and illustrate the power dimension in the academic literacies perspective.

Writing for policy-makers and the general public represents a more complex negotiation, one that highlights identity and meaning making (Lea and Street 2006). On one hand, academics are the preferred target group for most of the informants. Harald even went so far to say that non-academic pieces (op-eds, policy briefs, or reports) felt 'halffinished.' On the other hand, several informants, such as Ron, felt that reaching a nonacademic audience is precisely what makes their work meaningful and reflected their identities as a 'peace researcher':

I feel very strongly that it's the duty of any researcher in an institute such as this, working with peace and conflict, to engage with the public [and policymakers]. And anyone who is not interested in doing that shouldn't be working here.

Thus, negotiations about non-credited output revolved around the researchers' identities as peace researchers and being responsible staff members. In other words, not 
producing things that 'count' in productivity indicators does not necessarily reflect a failure to produce things that are important for other aspects of a researcher's role.

\section{Collaboration}

In Norway, the decision to co-author has a very direct impact on productivity statistics because authorship is fractionalized: you receive only a portion of the points awarded for that publication. This raises the question of why researchers would co-author when they could avoid it. At PRIO, there was a clear relationship between methodological orientation and the decision to co-author that mirrors the relationship between natural sciences and social sciences (Bazeley 2006). Quantitative researchers described co-authorship as not only more fun, but also a strategy to help them write more effectively. Similar to what Tschannen-Moran and Nestor-Baker (2004) describe, Anne said that working with co-authors provides 'safety in numbers': '[Co-authoring] feels like there's an extra safety net because someone else has also has a vested interest in it, and someone else also thinks it's interesting and good.'

In contrast, qualitative and theoretically oriented researchers described co-authoring as having 'high transaction costs' because they have to spend so much time agreeing on basic premises, as well as managing to preserve their own voices as authors. Yet, they often choose to co-author because they feel it makes the product better in the end:

Sometimes your co-authors are right and you're wrong. ... Sometimes they suggest something that you haven't thought of. They bring experience, skills, expertise you don't have, so it definitely makes for a more superior piece of work in the end. (David)

Thus, the qualitative and theoretical researchers have to weigh a possibly better product against a potentially frustrating process. This negotiation looks different for quantitative researchers because, as they describe in the interviews, data-driven material is easier to divide up between co-authors, whereas concept-driven material requires co-authors to work more closely together. This is difficult to reflect in a single set of productivity indicators that applies to all. Using whole counts (where each co-author is credited with 'a publication') results in a disproportionate number of publications by authors in the natural sciences; however, fractionalizing co-authorship (as is done in Norway) reflects an assumption that co-authoring is mostly about 'dividing up the work.' Decisions about how to treat co-authorship in productivity indicators thus take on ideological significance (Lillis and Curry 2010) and affect how 'productive' one group appears relative to another (see, e.g. Piro, Aksnes, and Rørstad 2013).

Irrespective of methodological orientation, the decision to co-author reflected more personal aspects of their identity as writers and co-workers: almost all my informants said explicitly that they want to be seen as a person who is good to collaborate with, and that co-authoring helped them keep the process moving along because they knew that someone else was counting on them. As Harald said, 'When working with someone, you feel that you are immediately responsible, and that you have to keep up your part to make sure that things are progressing.' David spoke disparagingly about 'prima donnas' and said, 'I think it is very important to be somebody who does actually get things finished and is happy to share the credit with their co-authors.'

Two of my informants described how early experiences with co-authoring influenced their perception of themselves and their environment. Recounting a negative experience co-authoring with a supervisor who took credit for his work, one informant 
told me, 'I think I've seen some kind of dark, underbelly of academia. ... But, when you've seen that a couple of times, you're also going to start to get more wary.... I think it's a rotten, rotten thing, co-authorship.' In contrast, another young $\mathrm{PhD}$ student told me that co-authoring with a senior researcher was essential in his learning how to write academically, and now he feels more confident about solo authoring. These experiences are in line with the argument in Marchant, Anastasi, and Miller (2011) that early publication for doctoral students and support from supervisors can build confidence and increase a student's motivation to write and publish more, but also illustrate that the converse can be true as well.

\section{Quality}

The productivity measurement system in Norway gives more points to output that is published in highly ranked journals and presses. Behind the decision to submit to these more prestigious outlets, or indeed behind the decision to submit at all, is a negotiation about quality. 'You have to get the balance right between producing something, and producing original, novel work,' said David. Quality was an explicit concern for almost all informants. As Anne pointed out, 'There are different types of ready. There's ready to be published somewhere, on paper, or there's ready to be published somewhere great.' This draws attention to how my informants see themselves as scholars.

Although several informants said that the wait involved in multiple rounds of polishing can be worth it if the product is well received in the end, delays can further increase the pressure to produce high-quality work, making submission even more difficult. Thus, the negotiation between quality and simply finishing (Murray and Moore 2006) can be a difficult one - sometimes even paralyzing - particularly for younger researchers. Frida described a 'nemesis' article that had gotten very good feedback at an early stage: The pressure to generate an excellent article 'just made it impossible for me to ever feel that I could get an article to a level that satisfied the expectations I felt from the outside world. ... it's just never good enough.' Several of my younger informants described a vicious cycle of low productivity creating negative thoughts, and negative thoughts making it difficult to produce, a phenomenon also described by Sherry et al. (2010). This is particularly dangerous for non-tenured staff because an apparent lack of productivity could jeopardize a potential permanent position.

Some had developed strategies for addressing their own insecurity about knowing when something was 'good enough.' Many, particularly the junior researchers, sought an outside opinion - usually a colleague whose opinion they could trust. The more experienced writers were more pragmatic: rather than focusing on quality, they did the best they could within a given deadline. One commented that he would consciously submit articles when they were about $80 \%$ finished because 'there's a diminishing return' in continuing to polish after a certain point. But he was not entirely comfortable with this tendency, and there seemed to be a general feeling, especially among the younger informants, that submitting anything other than your best work was morally questionable. Harald emphatically pointed out that 'one of the things I really don't do, I've seen as a peer reviewer that many others do, is to send a first draft into the journal - and then hope that the editor won't notice.'

This moral stance extends also to recycling previous work. While 'salami publishing' and other strategies to maximize the number of publications from a given project might well increase productivity statistics, these strategies clashed with PRIO 
researchers' ideas about good academic writing. Harald recalled a time he attempted to maximize exposure of his findings by creating more than one output targeted at different audiences: 'I thought it was a good idea while I was doing it, but now it feels kind of cheap.'

The negotiations over quality are thus not only related to whether or not a researcher aims for a prestigious journal or press, but also to whether things get finished at all. Low productivity may not be related to lack of writing activity, but to issues of identity (Ivanic 1998) - in the case of my informants, high ambitions and stringent definitions about what is considered original work and acceptable repurposing (Sherry et al. 2010).

\section{Process}

Productivity is ultimately related to getting words on paper: 'I think more than anything else, to be a researcher is to be a writer,' said Harald. While all my informants understood the need to produce writing, most were struggling to understand how the writing process works and what specifically would work for them. Even the top producers among my informants talked about the difficulty: 'I don't think we get through any writing process without a number of instances of true despair,' said Erik.

Perhaps the biggest difference between the most and least productive informants was an awareness and acceptance of this process as natural. Many of the junior researchers indicated that they felt that they were somehow 'doing it wrong,' which mirrors the student experience (Gourlay 2009). The more experienced writers seemed less concerned about whether they were doing it the 'right way' and more concerned about what worked for them as individuals - specifically their own strategies for disengaging from other tasks (Murray 2013), and engaging with writing, including starting and finishing (Murray and Moore 2006). These strategies all reflected different sites of negotiation.

Disengaging with other tasks was often reported as a struggle to prioritize competing institutional expectations. One informant with a large administrative burden said that 'you feel you are being pulled in all sorts of directions.' Several informants said that administrative tasks received priority because they affect other people, whereas the writing affects only themselves. One admitted to occasionally hiding behind administrative tasks to avoid difficult writing.

Disengaging was not limited to tasks within the institutional setting. An overarching negotiation for many informants was balancing life as a researcher with family life. Many have had to adapt their daily rhythms: Hans, for example, explained that he used to prefer writing in the evening when he was 'in the mood for it,' but now that he has young children, 'I don't have evenings anymore for that kind of stuff.'

A common strategy to maintain motivation was to change writing locations - to write at home, in a café, at a library, etc. (Murray 2013). Previous policy at PRIO was to discourage working away from the office because it was considered threatening to PRIO's identity as an interdisciplinary workplace where researchers would actively collaborate: empty offices might suggest that PRIO was merely a 'researcher hotel.' However, this policy has been relaxed and researchers can freely work away from the office one day a week, although some still feel unsure about how accepted it really is.

For the most productive writers, physical location was less important than the decision to simply prioritize writing over other tasks, even at the expense of feeling 
like you might be letting others down. Erik explained that getting writing done required that he consciously set aside a specific time to write:

Sometimes at dinnertime, I think 'Well, tomorrow maybe I have the opportunity to devote time after lunch to writing, but I'll decide when I get up,' and I sort of leave it hanging there. That's already a decision not to write.

Engaging with writing for many involved discussing their work with other researchers. Kyrre explained that researchers 'are not happy if we don't get to discuss our ideas with other people.' Yet, this does represent a genuine negotiation: while too little interaction with others can reduce the quality of academic work and increase isolation, too much interaction (also with respect to co-authoring and feedback) can make it not only difficult to finish, but also threaten the author's voice and sense of ownership (Ivanic 1998).

Attending conferences was reported as a common strategy for strategic engagement with other scholars. Most emphasized the networking function, in line with, for example, Salaran et al. (2010). The main negotiation here was to find the right balance of how many, and which ones, to attend. The positive aspects of networking had to be weighed against the time-consuming aspect, and the intimacy of smaller workshops had to be weighed against the breadth and prestige of larger conferences.

Engaging with writing was also about deciding which writing project(s) to engage with. Most were juggling several different writing projects at once. While a few found this distracting, many did this strategically to increase motivation for each project. But this made it difficult to finish any of them. The projects that generally received priority were co-authored ones or those with a clear deadline. Sarah pointed to an article that needed about three days of work to finish, but has been untouched for six months 'because I don't have a deadline. If I had had a deadline ... I would have found those three days.'

In general, the more experienced writers seemed to better understand their own writing process, which not only underscores the importance of learning, but also suggests that a better predictor of productivity might be writing experience rather than age, as suggested in the productivity literature (e.g. Costas, Leeuwen, and Bordons 2010).

\section{An integrated theoretical model of research productivity}

My overarching argument, as depicted in Figure 1, is that individual research productivity is not simply a function of observable individual or institutional characteristics (as shown by the thin lines moving from the outer boxes to 'Productivity'). Instead, as suggested by an academic literacies approach, productivity will depend greatly on the researcher's subjective understanding of their own identity (including abilities, desires, and fears); their subjective interpretation of their institutional environments (including expectations and values); and their own (perceptions of) agency within these constraints.

Because identities are complex and researchers belong to more than one institutional environment at a time, competing environmental demands and personal goals will - for some more than others - create sites of negotiation (Flower 1994; Ivanic 1998). Their sense of agency and other beliefs about themselves will affect how they negotiate between these competing goals and demands, and the outcome 


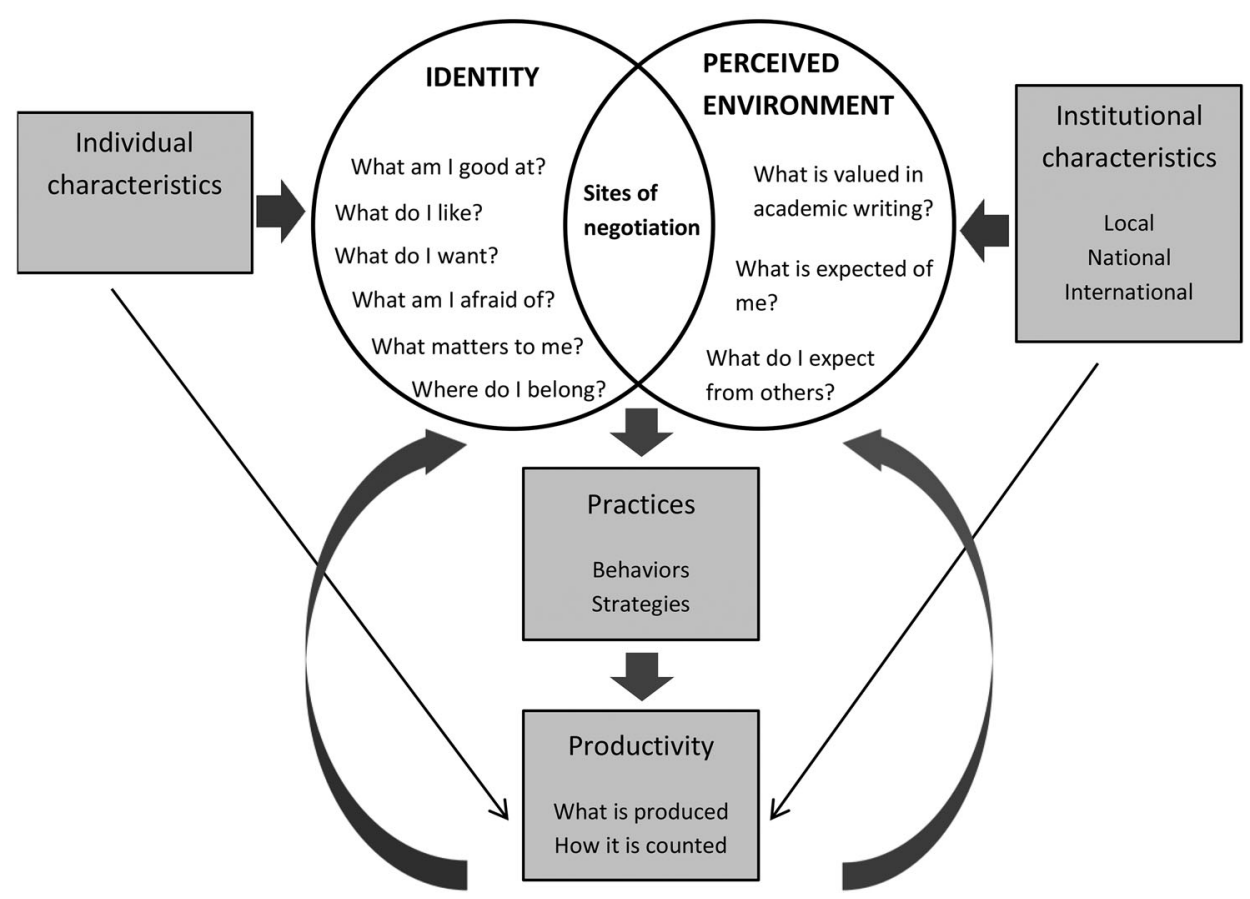

Figure 1. An integrated theoretical model of research productivity.

of these negotiations will be reflected in concrete practices (Barton and Hamilton 1998; Barton, Hamilton, and Ivanic 2000). The concrete practices - which in the case of PRIO researchers include decisions about what to produce, how high to aim (including how to know when something is finished), whether and how to co-author, and what to prioritize - will affect what the researcher produces, and how much of it. The extent to which this is seen as productive will depend on how productivity is measured in the various environments a researcher belongs to (Brandt and Clinton 2002).

The existing quantitative discourse focuses predominately on the outside boxes of this model. What the academic literacies perspective primarily brings to the model are the intersecting circles and thick arrows: the understanding of how identity, multiple communities, and negotiation make academic writing more than just a cognitive act.

However, an important contribution is also made from social cognitive theory: the feedback loops, shown by the curving arrows from productivity back to perceived identity and environment (Lawrence, Trautvetter, and Blackburn 1989). These loops reflect how the experience of publishing (or not publishing), and whether this output is valued (or not valued), will feed back into the researcher's beliefs about themselves (e.g. competent or incompetent) and their environments (e.g. fair or unfair) - which is likely to have a renewed effect on beliefs and practices (Lawrence, Trautvetter, and Blackburn 1989). This was illustrated by my informants who talked about 'vicious cycles' of low productivity making it harder to produce, as well as those who talked about how early co-authoring experiences shaped their perceptions of academia. 
Introducing this theoretical framework to the existing discourse on productivity invites a new range of research questions: Instead of just looking at the direct impact of individual attributes such as age, gender, and discipline, the researcher's gaze is directed to how these attributes work indirectly through identity, social power structures, and learning. And instead of conceptualizing the institutional environment exclusively in terms of the institution of employment, research can explore how academics perceive the different spheres of institutional influence (including national and international; disciplinary and thematic) and the ideologies they reflect. Lillis and Curry (2010) make significant headway in this respect by looking at how the increasing pressure to publish in English affects writing and publication practices for non-native English speakers.

\section{Conclusion}

The negotiations described by the PRIO researchers illustrate how they weigh (potentially conflicting) messages from their institutional environment(s) against (potentially conflicting) personal goals. The concrete practices that result depend on what kind of ideas they have about themselves: how they identify as writers, as peace researchers, as political scientists; what they find meaningful; what they desire, what they fear; and how much agency they feel they have. The outcome of these negotiations have a direct bearing on what they produce, how much they produce, and how fast it gets produced - and thus a direct bearing on their research productivity.

The intention of this article is not to suggest that the specific sites of negotiation reported by PRIO researchers are universal for all researchers. On the contrary, the purpose here was to illustrate how exploring a specific setting through the lens of academic literacies can add much needed nuance to the current, largely quantitative, discourse on research productivity. The case of PRIO shows how the experience of academic publishing differs from person to person, and perhaps more importantly, from group to group (e.g. qualitative versus quantitative researchers) - even within the same local setting - for reasons that have little to do with cognitive ability and writing skills, and a lot to do with the way productivity and academic writing are conceptualized and measured.

In the context of higher education administration, the academic literacies framework thus challenges the deficit model and throws a critical light on narrow definitions of research productivity. Many of the outputs that do not 'count' (e.g. grant proposals or policy-relevant documents) are crucial to maintaining the social relevance of academic research and the vitality of the individual institute. If researchers wrote only books, book chapters, and articles, the broader purpose of research and higher education would be undermined, and regardless of how much was published, our universities and research institutes would surely perish.

\section{Acknowledgements}

I gratefully acknowledge the support and feedback I received from my two supervisors at the Institute of Education, Dr Lesley Gourlay and Professor Richard Andrews.

\section{Disclosure statement}

No potential conflict of interest was reported by the author. 


\section{Funding}

I am also grateful to the Peace Research Institute Oslo (PRIO) for funding this doctoral research and to the researchers who participated in this study.

\section{References}

Acker, Sandra, and Carmen Armenti. 2004. "Sleepless in Academia." Gender and Education 16 (1): 3-24.

Alexander, F. King. 2000. "The Changing Face of Accountability: Monitoring and Assessing Institutional Performance in Higher Education." The Journal of Higher Education 71 (4): 411-31.

Bandura, Albert. 1991. "Social Cognitive Theory of Self-Regulation.” Organizational Behavior and Human Decision Processes 50: 248-87.

Barton, David, and Mary Hamilton. 1998. Local Literacies: Reading and Writing in One Community. London: Routledge.

Barton, David, Mary Hamilton, and Roz Ivanic. 2000. Situated Literacies: Reading and Writing in Context. London: Routledge.

Bazeley, Pat. 2006. "Research Dissemination in Creative Arts, Humanities and the Social Sciences." Higher Education Research \& Development 25 (3): 307-21.

Bentley, Peter James. 2011. "Gender Differences and Factors Affecting Publication Productivity Among Australian University Academics.” Journal of Sociology 48 (1): 85-103.

Blackburn, Robert T., and Richard J. Bentley. 1993. "Faculty Research Productivity: Some Moderators of Associated Stressors." Research in Higher Education 34 (6): 725-45.

Bland, Carole J., and Mack T. Ruffin. 1992. "Characteristics of a Productive Research Environment: Literature Review." Academic Medicine 67 (6): 385-97.

Brandt, Deborah, and Katie Clinton. 2002. "Limits of the Local: Expanding Perspectives on Literacy as a Social Practice.” Journal of Literacy Research 34 (3): 337-56.

Costas, R., van Leeuwen, T. N., and Bordons, M. 2010. "A Bibliometric Classificatory Approach for the Study and Assessment of Research Performance at the Individual Level: The Effects of Age on Productivity and Impact." Journal of the American Society for Information Science and Technology, 61: 1564-1581. doi:10.1002/asi.21348

Creamer, Elizabeth G. 1998. "Assessing Faculty Publication Productivity: Issues of Equity." In ASHE-ERIC Higher Education Report, edited by Lynne J. Scott, 91. Washington, DC: The George Washington University, Graduate School of Education and Human Development.

Fairweather, James S. 2002. "The Mythologies of Faculty Productivity: Implications for Institutional Policy and Decision Making." The Journal of Higher Education 73 (1): $26-48$.

Flower, Linda. 1994. The Construction of Negotiated Meaning: A Social Cognitive Theory of Writing. Carbondale, IL: Southern Illinois University Press.

Gibbons, Michael, Camille Limoges, Helga Nowotny, Simon Schwartzman, Peter Scott, and Martin Trow. 1994. The New Production of Knowledge: The Dynamics of Science and Research in Contemporary Societies. London: Sage.

Gourlay, Lesley. 2009. "Threshold Practices: Becoming a Student through Academic Literacies." London Review of Education 7 (2): 181-92.

Hockey, Jenny, and Martin Forsey. 2012. "Ethnography is not Participant Observation: Reflections on the Interview as Participatory Qualitative Research." In The Interview: An Ethnographic Approach, edited by Jonathan Skinner, 69-87. London: Bloomsbury Academic.

Ivanic, Roz. 1998. Writing and Identity: The Discoursal Construction of Identity in Academic Writing. Amsterdam: John Benjamins.

Kyvik, Svein. 1991. Productivity in Academia: Scientific Publishing at Norwegian Universities. Vol. 5, Studier i jus og samfunnsvitenskap. Oslo: Universitetsforlaget.

Lawrence, Janet H., Lois C. Trautvetter, and Robert T. Blackburn. 1989. "Predicting Faculty Publication Output: Evaluation of a Model Across Institutional Types." Paper presented at the Annual Meeting of the Association for the Study of Higher Education, Atlanta, GA, November 2-5. http://eric.ed.gov/?id=ED313967.

Lea, Mary R. 2004. "Academic literacies: A pedagogy for Course Design.” Studies in Higher Education 29 (6): 739-56. 
Lea, Mary R., and Barry Stierer. 2009. “Lecturers' Everyday Writing as Professional Practice in the University as Workplace: New Insights into Academic Identities." Studies in Higher Education 34 (4): 417-28.

Lea, Mary R., and Brian V. Street. 1998. "Student Writing in Higher Education: An Academic Literacies Approach." Studies in Higher Education 23 (2): 157-72.

Lea, Mary R., and Brian V. Street. 2006. "The 'Academic Literacies' Model: Theory and Applications." Theory Into Practice 45 (4): 368-77.

Lillis, Theresa. 2003. "Student Writing as 'academic literacies': Drawing on Bakhtin to Move From Critique to Design." Language and Education 17 (3): 192-207.

Lillis, Theresa, and Mary Jane Curry. 2006. "Professional Academic Writing by Multilingual Scholars: Interactions with Literacy Brokers in the Production of English-Medium Texts." Written Communication 23 (1): 3-35.

Lillis, Theresa, and Mary Jane Curry. 2010. Academic Writing in a Global Context: The Politics and Practices of Publishing in English. London: Routledge.

Lillis, Theresa, and Mary Scott. 2007. "Defining Academic Literacies Research: Issues of Epistemology, Ideology and Strategy." Journal of Applied Linguistics 4 (1): 5-32.

Marchant, Teresa, Naomi Anastasi, and Peter Miller. 2011. "Reflections on Academic Writing and Publication for Doctoral Students and Supervisors: Reconciling Authorial Voice and Performativity." International Journal of Organisational Behaviour 16 (2): 13-29.

Merton, Robert K. 1968. "The Matthew Effect in Science: The Reward and Communication Systems of Science are Considered." Science 159 (3810): 56-63.

Murray, Rowena. 2013. "It's not a Hobby: Reconceptualizing the Place of Writing in Academic Work." Higher Education 66: 70-91.

Murray, Rowena, and Sarah Moore. 2006. The Handbook of Academic Writing: A Fresh Approach. Berkshire: Open University Press.

Nygaard, Lynn P. 2014a. "The Professional without a Profession: An Entrepreneurial Response to Supercomplexity in Research Environments?" Educate 14 (3): 22-31.

Nygard, Lynn P. 2014b. "Research Productivity as a Site of Negotiation: A Case Study at a Research Institute in Norway." Institute Focused Study, University of London.

Piro, Fredrik Niclas, Dag W. Aksnes, and Kristoffer Rørstad. 2013. "A Macro Analysis of Productivity Differences Across Fields: Challenges of Measurement of Scientific Publishing." Journal of the American Society for Information Science and Technology 64 (2): 307-20.

Salaran, Mohammed. 2010. "Research Productivity and Social Capital in Australian Higher Education." Higher Education Quarterly 64 (2): 133-48.

Sherry, Simon B., Paul L. Hewitt, Dayna L. Sherry, Gordon L. Flett, and Aislin R. Graham. 2010. "Perfectionism Dimensions and Research Productivity in Psychology Professors: Implications for Understanding the (mal)Adaptivelness of Perfectionism." Canadian Journal of Behavioural Science/Revue canadienne des sciences du comportement 42 (4): 273-83. doi:10.1037/a0020466

Street, Brian V. 2003. "What's 'new' in New Literacy Studies? Critical Approaches to Literacy in Theory and Practice." Current Issues in Comparative Education 5 (2): 77-91.

Teodorescu, Daniel. 2000. "Correlates of Faculty Publication Productivity: A Cross-National Analysis.” Higher Education 39: 201-22.

Trede, Franziska, Rob Macklin, and Donna Bridges. 2012. "Professional Identity Development: A Review of the Higher Education Literature." Studies in Higher Education 37 (3): 365-84.

Tschannen-Moran, Megan, and Nancy Nestor-Baker. 2004. "The Tacit Knowledge of Productive Scholars in Education." Teachers College Record 106 (7): 1484-511.

White, Charles S., Karen James, Lisa A. Burke, and Richard S. Allen. 2012. "What Makes a 'Research Star'? Factors Influencing the Research Productivity of Business Faculty." International Journal of Productivity and Performance Management 61 (6): 584-602.

Williams, Heather A., and Joe W. Kotrlik. 2004. "A Mediated Hierarchical Regression Analysis of Factors Related to Career Research Productivity of Human Resource Education and Development Postsecondary Faculty." In Academy of Human Resource Development International Conference (AHRD), 1119-26 (Symp. 52-1). Austin, TX. 